\title{
Concentration of transunsaturated fatty acids in the adipose body tissue of decedents dying of ischaemic heart disease compared with controls
}

\author{
LEO H THOMAS, J A WINTER, AND R G SCOTT \\ From the Departments of Science and Mathematics/Computer Science, Polytechnic of Wales, Pontypridd, \\ Mid-Glamorgan CF37 1DL, UK
}

SUMMARY The constituents of the fat of 136 decedents who had died of ischaemic heart disease are compared with the constituents of the fat from 95 controls who had died from other causes. The cases had a lower concentration of fatty acids $(\mathrm{L})$ characteristic of ruminant animal fat and a higher concentration of total transunsaturated acids $(T)$, but the concentrations of certain higher $\left(C_{20}\right.$ and $\mathrm{C}_{22}$ mostly monoenoic) acids $(\mathrm{H})$ were similar. The ratio $\mathrm{T} / \mathrm{L}$ was higher in the cases, which suggests that the cases may have consumed more hydrogenated fats in life than had the controls. The ratio $\mathrm{T} / \mathrm{L}$ increased linearly with $\mathrm{H}$ within both the case and control specimens, which suggests in view of the similarity in the mean levels of $\mathrm{H}$ that the difference in trans contents may be concentrated in the lower (18:1 and 16:1) trans acids.

In previous papers ${ }^{1,2}$ we examined samples of body fat taken from people who had died of ischaemic heart disease (cases) and compared them with samples taken from people who had died from unrelated causes (controls)

We studied in particular two groups of fatty acids; firstly, 14:1, 15:0, 15:0br, 15:1, 16:0br, 17:0, 17:1 the sum of which we labelled L; and, secondly, 20:0, $20: 1,20: 2,20: 3,22: 0$, and 22:1, which we called "higher fatty acids" and collectively labelled $\mathrm{H}$. We also measured by infrared spectroscopy the total transunsaturated fatty acids, irrespective of chain length, which we labelled $T$.

The body fat from cases had a significantly lower concentration of $\mathrm{L}$ acids than that taken from controls, but the concentration of $\mathrm{H}$ acids did not differ. The cases had a higher concentration of $T$, a difference that was not statistically significant. But when we considered the ratio $\mathrm{T} / \mathrm{L}$ then the cases had a significantly higher ratio than the controls.

The $L$ acids are typical of ruminant-animal fat and the trans acids arise mostly from the commercial hydrogenation of soft fats and oils. We therefore suggested that the cases had consumed a higher proportion of commercially hydrogenated fats and a smaller proportion of ruminant animal fat than had the controls.

We wished to analyse these results further, but our method of measuring trans acids by infrared spectroscopy did not allow us to distinguish the particular chain lengths of these acids; initially therefore, we approached the problem indirectly.

The trans acids in the diet may be subdivided according to chain length into:

(a) 16:1 trans and 18:1 trans which we describe as the "lower trans acids" and the sum of these we label $T_{L}$;

(b) the trans acids of chain length $\mathrm{C}_{20}$ and $\mathrm{C}_{22}$ which we describe as the "higher trans acids" and label $\mathrm{T}_{\mathrm{H}}$.

These two groups together make up the total trans acids (T) measured by the spectroscopic method.

The distribution of these acids in fats consumed in the United Kingdom varies from source to source..$^{3-7}$ These distributions are summarised below.

(1) Ruminant-animal fat (butter fat, beef, and mutton) contains $5-8 \%$ of $\mathrm{L}$ acids and $5-7 \%$ trans acids almost entirely as $T_{L}$ (with 18:1 trans predominating). It contains $1-2 \% \mathrm{H}$ acids.

(2) Pig fat contains up to $2 \% \mathrm{~L}$ acids, no $\mathrm{T}$ acids, and very little $\mathrm{H}$ acids.

(3) Other natural, unhydrogenated fats and oils have no $L$, no $T$, and-with the sole exception of rapeseed oil-very little $\mathrm{H}$ acids.

(4) Hydrogenated vegetable oils have virtually no $\mathrm{L}$ acids and very little $\mathrm{H}$ acids. The trans acid content depends on the cornmercial process used. Usually a lower limit of about $12 \%$ is set to ensure that the product will keep and an upper limit seems to be 
about $30 \%$. In the United Kingdom the average concentration in hydrogenated vegetable oils appears to be about $16 \%$, and this consists almost entirely of 18:1 trans acid.

(5) Hydrogenated marine oils which are much used in the United Kingdom ${ }^{8}$ have about $2 \%$ L acids and (according to source) $25 \%$ to $50 \%$ of $\mathrm{C}_{20}$ and $\mathrm{C}_{22}$ acids of composition similar to the $\mathrm{H}$ acids of our adipose tissue samples. ${ }^{2}$ About $90 \%$ of these higher acids in hydrogenated marine oils are in trans unsaturated form-that is as $T_{H}$. We have examined seven leading brands of margarine of high hydrogenated marine oil content, and it appears that in commercial practice a marine oil of mixed origin is used having a mean $\mathrm{H}$ content of about $35 \%$ and a mean total trans (T) content of about $50 \%$. Its $\mathrm{T}_{H}$ content was relatively constant (mean $34 \%, S D \pm 6$ ) but its concentration of $T_{L}$ (mean $16 \%$ ) was much more variable. Of particular relevance is the fact that the concentration of $16: 1$ trans varied widely between $4 \%$ and $13 \%$, with a most probable mean concentration of $8 \%$. Amounts of 16:1 trans in such margarines are therefore highly variable, even at similar levels of $H$.

The individual patterns of fat consumption will vary between individuals but the body fat composition will correspond with the dietary fat intake, ${ }^{2}$ and the ratio T/L should correlate with increased intake of hydrogenated fats. In the event of zero consumption of hydrogenated fat the ratio $\mathrm{T} / \mathrm{L}$ will be $0.8^{1}$ and the $T$ acids would be almost entirely in the form $T_{L}$. The ratio will rise with inclusion of hydrogenated vegetable or hydrogenated marine oils in the diet, and the increase will be accompanied by increasing amounts of $T_{L}$. Consumption of hydrogenated marine oil will also result in increase in $\mathrm{T}_{\mathrm{H}}$ and $\mathrm{H}$.

We concluded therefore that as hydrogenated marine oil is a major component of British margarines and shortenings the ratio $\mathrm{T} / \mathrm{L}$ should correlate with $\mathrm{H}$ and that the higher ratio found in our cases compared with our controls might be influenced by the amount of "higher fatty acids" that they consumed.

\section{Methods}

The selection of the cases and controls and the transport of the adipose tissue specimens to our laboratory have been described, ${ }^{1}$ as have the methods of chemical estimation. ${ }^{2}$ The proportions of the various fatty acids were measured by gas-liquid chromotography, and the proportion of $\mathrm{H}$ and $\mathrm{L}$ as defined were obtained by measurement from the charts. The total transunsaturated acids was measured by infrared spectroscopy. All readings were done without knowledge by the laboratory chemist at the time of analysis as to whether the specimen was obtained from a case or a control.

The data were analysed by analysis of covariance to determine the regression of $\mathrm{T} / \mathrm{L}$ on $\mathrm{H}$ within cases and controls.

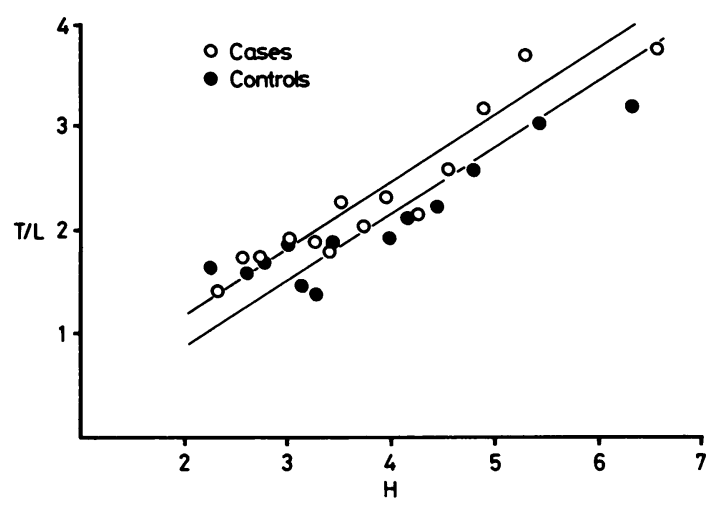

Association of high fatty acids $(H)$ with the ratio of transunsaturated acids (T) to $L$ acids in 136 cases and 95 controls.

Analysis of covariance of regression of $T / L$ on $H$ cases and controls

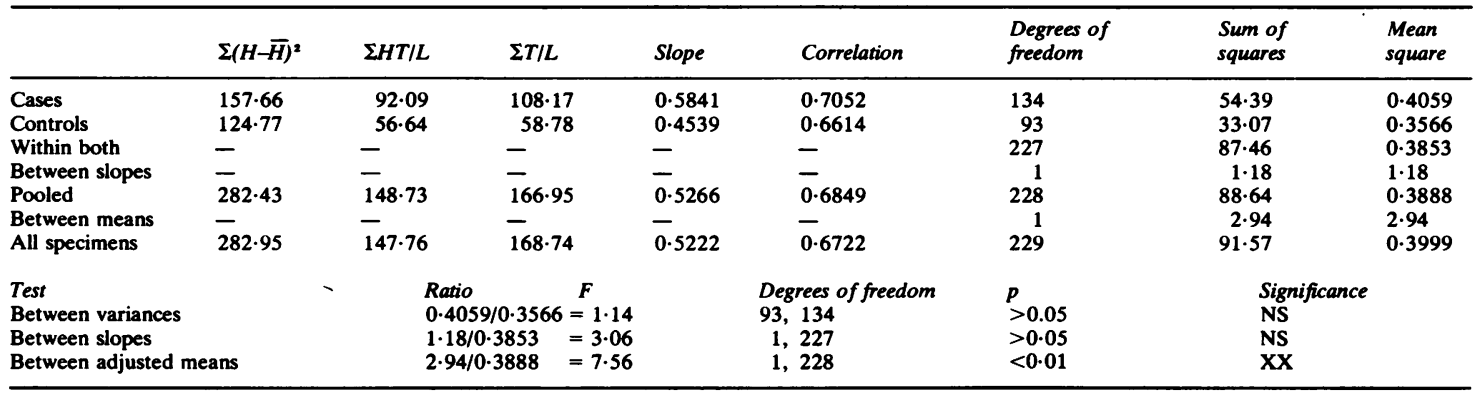




\section{Results}

There were 136 cases and 95 controls. There were wide overlapping ranges in both $\mathrm{H}$ and $\mathrm{T} / \mathrm{L}, \mathrm{H}$ ranged from $2.15 \%$ to $7.45 \%$ in cases and from $2.05 \%$ to $6.95 \%$ on controls, whereas $\mathrm{T} / \mathrm{L}$ ranged from 0.90 to 5.30 in cases and from 0.97 to 4.42 in controls. That $\mathrm{T} / \mathrm{L}$ increases with $\mathrm{H}$ for both cases and controls is apparent from the figure. The points plotted are mean values of $T / L$ against mean values of $H$, and each mean is that of an approximately constant number of individual values ( 7 for controls, 10 for cases).

The overall mean percentages of $\mathrm{H}( \pm$ SD) were $3.81( \pm 1.02)$ in cases and 3.91 $( \pm 1.14)$ in controls; the difference $(0 \cdot 10)$ was not statistically significant, $t=0 \cdot 78, p=0 \cdot 29$. The mean of the ratio $T / L( \pm S D)$ was $2.24( \pm 0.90)$ in cases and $2.06( \pm 0.79)$ in controls; the mean difference of 0.18 was not statistically significant, $t=1 \cdot 44, p=0 \cdot 14$. (It was shown previously, ${ }^{1}$ however, that when the decedents were matched for area of residence, the mean value of $\mathrm{T} / \mathrm{L}$ in cases was significantly higher than the mean value in the controls.)

The detailed analysis of covariance is given in the table, and in accord with our hypothesis there were highly significant correlations between $\mathrm{H}$ and $\mathrm{T} / \mathrm{L}$ both within the cases $\left(r_{1}=0.705\right)$ and within the controls $\left(r_{2}=0.661\right)$. The slopes of the two regression lines (fig) of $T / L$ on $H$ were $b=0.5841$ for cases and $b_{2}=0.4539$ for controls. As these regressions were not significantly different from one another we pooled the two regressions to give a pooled regression $b=0.5266$.

When the means of $T / L$ are now adjusted for the regression on $\mathrm{H}$ the difference between cases and controls becomes highly significant $(F=7 \cdot 56, p<$ $0 \cdot 01$ ).

\section{Discussion}

At comparable levels of $H$ then the cases have the higher value of $T / L$. There appears to be no explanation of this result other than that $(a)$ the case and control specimens have similar levels of "higher trans acids" and $(b)$ the cases have the higher value of 16:1 plus 18:1 trans acids relative to $L$.

For the United Kingdom, detailed knowledge relating to relative amounts of the various fatty components making up the total dietary fat is available, and the composition of the average England and Wales fatty diet may be calculated. The fatty acid composition of such diet was shown to agree well-subject only to body-desaturation of 16:0 to $16: 1$ and $18: 0$ to $18: 1$-with the average composition of the 95 control samples drawn widely from that population. ${ }^{2}$

On the premise therefore that population mean levels of trans and $L$ acids in adipose tissue reflect dietary intakes, we conclude that the cases consumed a higher amount of hydrogenated fat relative to ruminant-animal fat than did the controls.

The failure to detect any significant difference in the mean levels of $\mathrm{H}$ suggested to us that there was unlikely to be a significant difference in the levels of $T_{H}$ and so the difference observed between the mean values of $T$ must be largely attributed to differences in $T_{L}$.

This encouraged us to analyse the transunsaturated acids in further detail to see whether we could identify a difference between cases and controls specific for $T_{L}$.

We thank Dr P C Elwood, director, MRC Epidemiology Unit (South Wales), for his continued support and encouragement and Professor $\mathrm{H}$ Campbell of the Welsh National School of Medicine for his help and advice. We are in receipt of a grant from the Welsh Committee for Locally Organised Research.

Reprints from Leo $\mathrm{H}$ Thomas, Department of Science, The Polytechnic of Wales, Pontypridd, Mid-Glamorgan CF37 1DL.

\section{References}

${ }^{1}$ Thomas LH, Scott RG. Ischaemic heart disease and the proportions of hydrogenated fat and ruminant animal fat in adipose tissue at postmortem examination: a case/control study. J Epidemiol Community Health 1981; 35: 251-5.

${ }^{2}$ Thomas LH, Jones PR, Winter JA, Smith $\mathbf{H}$. Hydrogenated oils and fats; the presence of chemically modified fatty acids in human adipose tissue. Am J Clin Nutr 1981; 34: 877-86.

${ }^{3}$ Conacher HBS, Page BD, Chadha RK. Isomers of monoethylenic fatty acids in some partially hydrogenated marine oils. Journal of the American Oil Chemists' Society 1972; 49: 520-3.

${ }^{4}$ Ackman RG, Hooper SN, Hingley J. Monoethylenic fatty acids of a partially hydrogenated herring oil. Journal of the American Oil Chemists' Society 1971; 48: 804-6.

${ }^{5}$ Tiege B, Beare-Rogers JL. Cardiac fatty acids in rats fed marine oils. Lipids 1973; 8: 584-7.

${ }^{6}$ Hoelmer G, Aaes-Jorgensen E. Fatty acid composition of partially hydrogenated arachis, soya bean and herring oils and of normal, refined arachis oil. Lipids 1969; 4: 507-14.

${ }^{7}$ Lambertson G, Myklestad H, Braekkan OR. Fatty acid composition of commercial hydrogenated fish oils. Journal of Food Science 1966; 31: 48-52.

${ }^{8}$ Andersen AJC, Williams PN. Margarine, 2nd ed. London; Pergamon Press, 1965; 73.

${ }^{y}$ Davies OL, Goldsmith PL, eds. Statistical methods in research and production. 4th ed. Edinburgh: Oliver and Boyd, 1972: 178-236. 